Vol.: 5 Issue: 2 Date: 31.12.2021 Received: 20.10.2021 Accepted: 16.12.2021 Final Version: 31.12.2021

ISVOS Journal, 2021, 5(2): 200-209 - https://doi.org/10.47897/bilmes.1012541

\title{
The Impact of Middle-Aged and Older People's Preventive Health Behaviour and Trust in Government Performance during the Pandemic on Their Trust in COVID-19 Vaccine
}

\author{
Fuat YALMAN ${ }^{\mathrm{a}, 1}$, Yalçın KARAGÖZ \\ ${ }^{a, 1}$ Düzce University, Faculty of Business Administration, Department of Health Administration, Düzce, Turkey \\ ORCID ID: 0000-0002-1041-1837 \\ ORCID ID: 0000-0001-5642-6498
}

\begin{abstract}
The main purpose of this research is to determine the impact of people's preventive health behavior and trust in government performance during the pandemic on their trust in COVID-19 vaccine. The population of the research consisted of middle and advanced age group individuals who received service from pharmacies in the city center of Karabük. In the study, convenience sampling method was preferred due to the difficulty of reaching the participants during the COVID-19 pandemic process and 400 questionnaires were returned at the end of the data collection process. SPSS and AMOS package programs were used in the analysis of the data. Confirmatory factor analysis and path analysis techniques were applied to the data. The findings obtained by confirmatory factor analysis and path analysis showed that the construct validity of the model was ensured. According to the path analysis results, it was determined that the participants' protective health behavior $(\beta=0.339 ; \mathrm{p}<0.05)$ and their confidence in government performance $(\beta=0.265 ; \mathrm{p}<0.05)$ affected their confidence in the COVID-19 vaccine statistically and positively. During the pandemic, their COVID-19 vaccine acceptance and COVID-19 vaccine confidence increase as people engage in more and more accurate preventive health behavior and have confidence in government performance.
\end{abstract}

Keywords: "COVID-19 pandemic, vaccination, preventive health behaviour, trust in government performance"

\section{Introduction}

Due to the spread of the virus, which was first seen in Wuhan, China in December 2019, defined as "Novel Coronavirus Disease/COVID-19" and caused a deadly disease, to Europe and America in a short time, it has been declared as a pandemic (global epidemic) as of March 11, 2020 by World Health Organization. The coronavirus disease, called COVID-19, is a newly discovered type of infectious disease and its etiology is not fully known. By the end of May, COVID-19 had infected more than five million people in 215 countries or territories and caused more than 300,000 deaths worldwide [1].

The coronavirus disease is a deadly disease that still continues to affect many countries around the world. The main reason for this is that COVID-19 has become a serious public health problem worldwide [2]. During the COVID-19 outbreak, governments have taken a number of strong interventions to prevent and control the rate of spread of the epidemic, including city lockdowns, travel bans, quarantine, mask requirement and social distancing policies [3]. These measures have effectively slowed down the spread of the epidemic, but despite the measures taken, it is observed that COVID-19 is still increasing worldwide. In some cities and regions where the spread of the virus is effectively controlled, it has been observed that the epidemic started to increase again as the control measures taken to prevent the epidemic were relaxed [4]. At the same time, as the COVID-19 pandemic has had a devastating impact on many areas around the world, this has demonstrated how essential the need for policies to mitigate the spread of the epidemic is [5].

The main strategy followed by almost every country around the world for the transmission of the virus is to reduce the transmissibility of the disease, usually through non-pharmaceutical interventions, including the implementation of a mask policy, hand cleaning, social distancing, travel restrictions, school closures, and partial or total lockdowns [6]. So far, it has been seen that non-pharmaceutical interventions can slow the progression of the disease, but it has been concluded that the most promising strategy to further limit the epidemic and reduce the mortality and morbidity rates caused by the epidemic is to take advantage of the possibilities of medical technology. Such medical technologies are known to enable the development of effective, safe and affordable antiviral agents and vaccines [7].

\footnotetext{
${ }^{1}$ Sorumlu Yazar. Tel.: +90-0380-542-1370

E-posta adresi: fuatyalman@duzce.edu.tr
} 
The lack of an available vaccine or effective treatment in the fight to control the spread of COVID-19 in the early stages of the epidemic has led to the implementation of quarantines and lockdowns, social distancing measures, the use of mandatory masks and travel restrictions in all countries around the world. At the same time, these measures have caused a great deterioration in the physical and psycho-social well-being of people and a great decline in the global economy. In addition, the multifaceted catastrophic consequences associated with the COVID-19 outbreak have intensified international efforts to develop an effective prevention method to keep outbreaks under control. One of these efforts is vaccine studies [8]. Therefore, in the very early stages of the pandemic, vaccine development studies have started rapidly in order to reduce the negative effects of the current global crisis [9]. Vaccines are one of the most reliable, cost-effective public health interventions ever implemented, saving millions of lives each year $[10,11]$.

Despite all the known benefits of vaccines, people may exhibit negative attitudes and behaviors towards vaccines due to doubts about the safety and efficacy of vaccines, and distrust of governments and healthcare professionals [12]. For this reason, in the last 20 years, anti-vaccination movements have increased more in developed and developing countries, and there has been a decrease in the number of parents who have their children vaccinated, especially with the spread of the Internet. Insufficient knowledge of parents, the target group of such anti-vaccine movements, also made this group vulnerable and open to manipulation $[13,14]$. Lack of knowledge about vaccine preventable diseases, low level of health literacy, doubts about the efficacy and safety of vaccines, distrust of governments and health workers, fear of side effects of vaccines, news of anti-vaccine coverage in the media, perception of childhood specificity of vaccination, selective rather than general practice of adult immunity Reimbursement problems regarding adult immunization and the absence of an adult vaccination scheme cause the adult vaccination rates to be low in our country [15].

The concept of trust in the state has been defined as the cornerstone of the political system, especially in crises such as natural disasters, economic crises or pandemics [16]. Trust in government represents people's trust or satisfaction with government performance and the perceived reputation of government [17, 18]. Trust in the state develops sociability spontaneously and naturally, which leads to cooperative, altruistic and cross-border behavior in social activities [19]. Previous studies have found that high levels of trust in government follow a range of government recommendations and prosocial behaviors, such as adopting preventive behaviors to avoid swine flu [20], getting seasonal flu shots [21], and making economic sacrifices for the environment. demonstrated that it was associated with greater willingness to comply [22].

Emerging theoretical and empirical evidence has shown that trust in government is crucial for compliance with social policies and preventive behaviors based on behavioral responses of the public [23, 24, 25]. Given the importance of building public confidence during the pandemic, there is an urgent need to identify determinants of confidence in the COVID-19 vaccine regarding the adequacy and effectiveness of COVID-19 control. Therefore, it is important for the control of COVID-19 to understand the relationship between trust in government and the adoption of preventive behaviors and to explore the various determinants of trust in government during the pandemic. The aim of this study; The aim is to determine the impact of people's protective health behavior during the pandemic and their reliance on government performance on their confidence in the COVID-19 vaccine. The results of the current study; It will help policy makers to highlight the importance of vaccination to society, prevent further lethality, especially by vulnerable patients, and conduct proactive campaigns and well-designed strategies by promoting vaccine uptake and acceptance to limit the spread of the pandemic.

\section{Material and Methods}

This research was carried out with ethical approval from Düzce University Scientific Research and Publication Ethics Committee (Date: 09.04.2021, decision no: 2021/112).

\subsection{Conceptual Model of Research and Hypothesis Development}

Similar model studies were examined and a conceptual/theoretical model of the research was created with the literature review carried out during the model development phase. Vaccine acceptability; It has been reported that it is determined by three factors: trust, convenience and satisfaction [26]. Trust; confidence in the safety and efficacy of the vaccine is defined as confidence in the delivery system as the healthcare system, and trust in policy makers [27]. Many people appear to have doubts about vaccine safety, and this is seen as a major challenge by healthcare providers, policymakers, community leaders and governments to increase the prevalence of vaccine adoption [28, 29, 30]. In addition, emerging theoretical and empirical evidence has shown that trust in government is crucial for compliance with social policies based on the behavioral responses of the public $[23,24,25]$. In previous studies in the literature, a high level of trust in government has been associated with a number of government recommendations and positive social benefits, such as adopting preventive behaviors to avoid swine flu [20], getting seasonal flu vaccination [21], and making economic sacrifices for the environment. showed that it is associated with more willingness to comply with behaviors [22]. In a longitudinal study of 633 participants in Singapore during the January-April 2020 period, trust in government communication was found to be positively associated with the likelihood of adopting protective behavior [31]. 
Therefore, it is important for the control of COVID-19 to understand the relationships between trust in government and government performance and the adoption of preventive health behaviors and trust in the COVID-19 vaccine, and to explore the various determinants of COVID-19 vaccine trust during the pandemic. Determining the effect of people's protective health behavior during the pandemic and their confidence in government performance on their confidence in the COVID-19 vaccine by structural equation modeling and pathway analysis constitutes the subject and conceptual model of the research. In the light of these studies, the following hypotheses have been developed:

" $\mathrm{H}_{1}$ : The way people display preventive health behaviors during the pandemic has a significant impact on their confidence in the COVID-19 vaccine."

" $\mathrm{H}_{2}$ : "People's confidence in government performance during the pandemic has a significant impact on their confidence in the COVID-19 vaccine."

The relationships between the conceptual model of the research are shown in Figure 1.

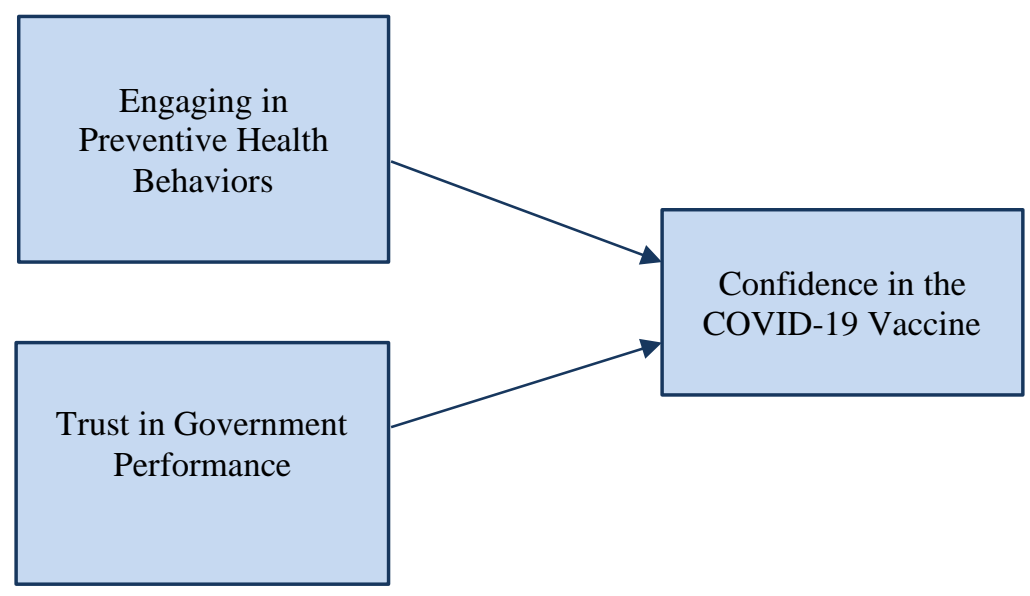

Fig. 1. Conceptual Model of the Research

\subsection{Research Population and Sample}

The population of the study consisted of middle-aged and elderly individuals who received service from pharmacies in Karabük city center and were thought to be most affected by the COVID-19 epidemic. Severe COVID-19 can occur in healthy individuals of any age, but it is predominantly more common in adults with advanced age or underlying medical comorbidities [51]. In clinical studies, it has been reported that those who are most and most frequently affected by COVID-19 are middle-aged and older individuals $[52,53]$. In a study based on Chinese data, it was reported that the rates of hospitalization with the diagnosis of COVID-19 increased with age, being $1 \%$ for those aged 20 to 29 years, $4 \%$ for those aged 50 to 59 years, and $18 \%$ for those over 80 years of age [54]. Therefore, the sample group of the research consisted of middle-aged and older individuals.

Due to the difficulty of transportation, cost and time constraints for middle-aged and older individuals, who are thought to be the most and most affected by the COVID-19 pandemic, only individuals who applied to pharmacies located in the city center of Karabük were included in the sampling and convenience sampling method was preferred. A total of 700 surveys were planned to represent the universe more strongly, but 437 surveys were returned. In addition, 37 questionnaires were not included in the analysis because they were filled incompletely and incorrectly.

\subsection{Data Collection Method and Creation of Scales}

Face-to-face survey technique was used to obtain the data. In the first part of the questionnaire, it was stated that participation in the study was voluntary, that the data obtained would not be used for any purpose other than research and would not be shared with other individuals or organizations. The study was carried out as a cross-sectional study of the middle and elderly population of the society, which receives service from pharmacies in the city center of Karabük and is thought to be most affected by the COVID-19 epidemic. While preparing the developed questionnaire, a detailed literature review was made, it was discussed in detail with academicians and experts specialized in the field of Public Health and Health Management, and its final version was created. Then, for the pilot application, around 20 respondents selected from the community where the survey will be applied were utilized. With the pilot application, the questions are made understandable by everyone in the same way. Scale items are rated as 1-Strongly Disagree, 2-Disagree, 3-Neither Agree nor Disagree, 4-Agree, 5-Strongly Agree. As a result of expert opinions, the content validity index of the draft scale was calculated as 0.89 . The questionnaire form consists of four parts in 
total. In the first part, there are statements to measure the protective health behavior of people during the pandemic, which consists of five propositions; in the second part, there are statements to measure people's confidence in government performance during the pandemic, which consists of four propositions. In the third part, there are statements about measuring the confidence levels of the participants for the COVID-19 vaccine, which consists of three propositions, while the last part includes the basic characteristics of the participants and their thoughts about the origin of the COVID-19 virus.

\subsection{Scales Used in the Research}

In the study, Han et al. [32] developed a questionnaire was used to measure the participants' protective health behavior and their level of confidence in government performance. The questionnaire that measures people's protective health behavior during the pandemic consists of five propositions, and the questionnaire that measures their confidence in government performance consists of four propositions. To measure the COVID-19 vaccine confidence levels of the participants, Lin et al. [33] has benefited from the questionnaire developed by. The questionnaire, which measures the general confidence levels of the participants for the COVID-19 vaccine, also consists of 3 propositions in total.

\subsection{Data Analysis Method}

SPSS and AMOS statistical analysis programs were used together for the analysis of the data set within the scope of the research. First of all, reliability analysis was made on the data. Then, confirmatory factor analysis was performed to ensure structural validity and the structural validity of the model was tested. Finally, path analysis was performed to determine the relationships between the variables.

\subsection{Data Set Analysis Criteria}

It was checked whether the standardized loadings of the observed variables on each construct were significant, and whether the superior convergent validity was higher than 0.5 . Composite reliability test was then performed to check the validity. If the mean variance extracted for each construct is greater than the variance shared with other constructs, discriminant validity was checked.

\section{Results and Discussion}

\subsection{Reliability of Research Data}

In the study, reliability measurement was made by calculating the Cronbach alpha value of each variable. The factors of people's display of protective health behavior during the pandemic, which constitute the variables of the research, were subjected to reliability analysis with five questions, the factors of trust in government performance with four questions, and the questions measuring the COVID-19 vaccine confidence levels of the participants with three items. Reliability coefficients for variables; "Engaging in Preventive Health Behaviors Cronbach's Alpha Coefficient = 0.840"; "Confidence in Government Performance Cronbach's Alpha Coefficient = 0.883" and "COVID-19 Vaccine Confidence Cronbach's Alpha Coefficient=0.830" were found. The overall reliability coefficient is Cronbach's Alpha $=0.872$. Therefore, when all dimensions are taken into account, it is seen that the reliability of the research is quite high.

\subsection{Demographic Findings}

While $41 \%$ of the individuals participating in the research were female and $59 \%$ were male; $42 \%$ of them are in the age group of $36-45,38 \%$ are in the age group of $46-55$, and $20 \%$ are in the age group of 56 and over. 58\% of the participants stated that they were mostly university graduates. In terms of the institution they work for, $37 \%$ of the participants stated that they work in a public institution, $33 \%$ work in the private sector, $14 \%$ are retired, $13 \%$ are housewives, and 3\% are self-employed. Finally, $68 \%$ of the participants stated that they thought the COVID-19 virus was of natural origin (originated from wildlife), and $32 \%$ of them thought that it was a virus of artificial origin (produced in a laboratory).

\subsection{Findings Related to Confirmatory Factor Analysis and Pathway Analysis}

Path analysis with hidden variables is an analysis that produces more reliable results than path analysis with observed variables. The diagrams of the model fit were obtained as follows. In this section, the degree of compliance of the data with the predicted model was tested by performing CFA on the factors of participants' protective health behavior, government 
performance confidence levels and COVID-19 vaccine confidence levels with the AMOS package program. The path diagram and goodness-of-fit results of the model are given in Figure 2 (Figure 2).

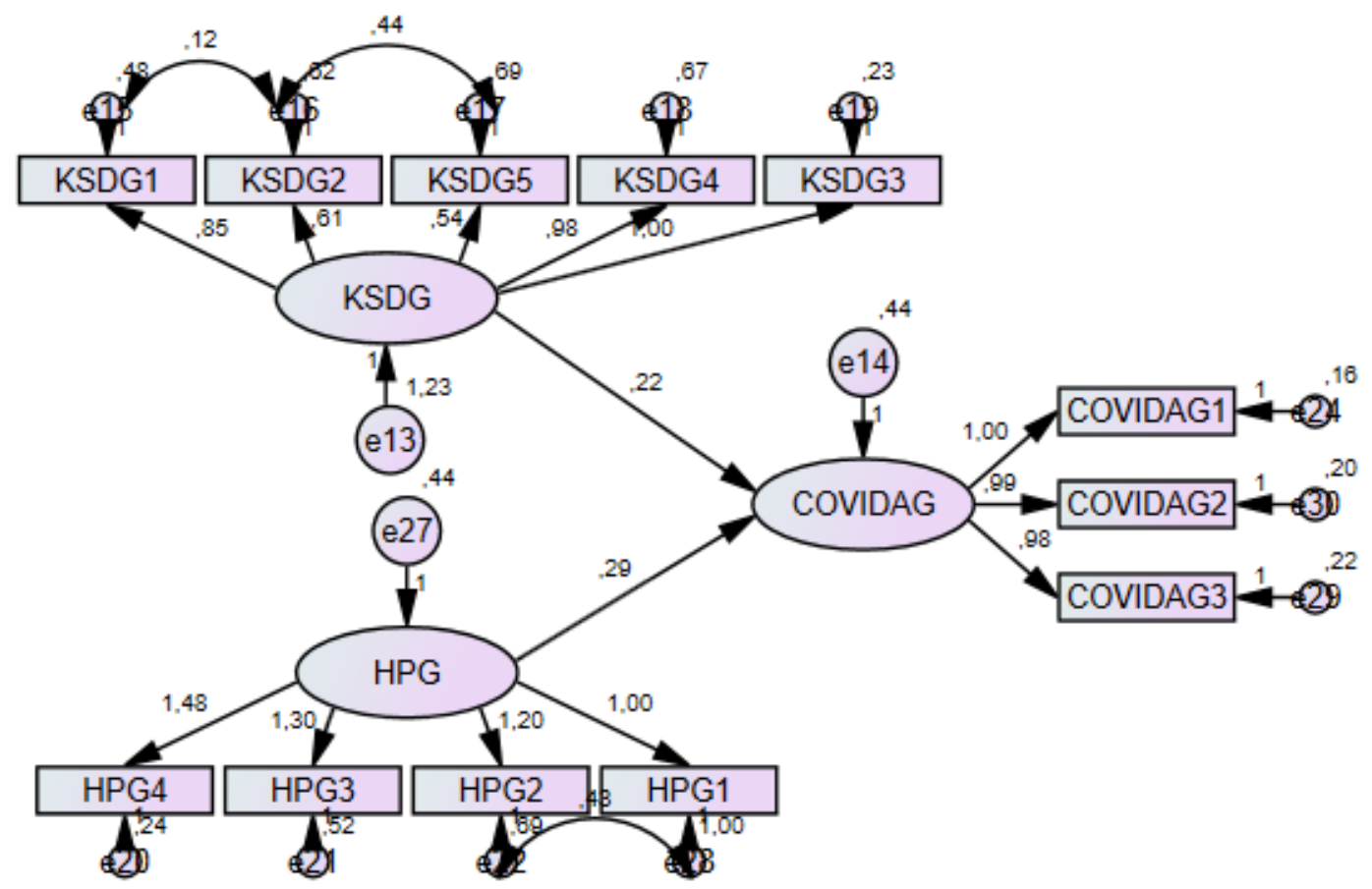

KSDG: Engaging in Preventive Health Behaviors; HPG: Confidence in Government Performance; COVIDAG: COVID-19 Vaccine Confidence

[(X²/df: 4.006; GFI: 0.942; NFI: 0.949; CFI: 0.961; RMR: 0.072; TLI: 0.948; IFI: 0.962; RFI: 0.932; AGFI: 0.908; RMSEA: 0.076)]

Fig. 2. Engaging in Preventive Health Behaviors - Confidence in Government Performance - COVID-19 Vaccine Confidence Path Diagram and Goodness of Fit Results

The $\mathrm{X}^{2} / \mathrm{df}$, RMR, GFI, NFI, IFI, TLI, CFI, AGFI values given above show that the model fit is achieved and the fit indices of the proposed research model are at an acceptable level of fit. There is no limit to the values to look up. The reported values may vary according to the values that the researcher wants to draw attention to. The fit values related to the created model are given below. At the same time, the findings obtained by confirmatory factor analysis revealed that the construct validity of the model was provided. The explained variances and reliability of the factors calculated to determine the validity and reliability of the path analysis are given in Table 1 below (Table 1).

Table 1. DFA Results for the Improved Measurement Model

\begin{tabular}{|c|c|c|c|c|c|c|c|}
\hline Observed Variables & $\begin{array}{c}\text { Latent } \\
\text { Variables }\end{array}$ & $\begin{array}{c}\text { Standardized } \\
\text { Regression } \\
\text { Coefficients }\end{array}$ & Estimate & $\begin{array}{c}\text { Standard } \\
\text { Error }\end{array}$ & $\begin{array}{c}\mathrm{T} \\
\text { Value }\end{array}$ & $\mathrm{P}$ & Cronbach's $\alpha$ \\
\hline \multirow{5}{*}{$\begin{array}{c}\text { Engaging in } \\
\text { Preventive Health } \\
\text { Behaviors (KSDG) }\end{array}$} & KSDG3 & .918 & 1.000 & & & & \\
\hline & KSDG1 & .808 & .854 & .037 & 22.940 & $* * *$ & \multirow{4}{*}{0.840} \\
\hline & KSDG2 & .650 & .608 & .037 & 16.632 & $* * *$ & \\
\hline & KSDG5 & .588 & .544 & .037 & 14.644 & $* * *$ & \\
\hline & KSDG4 & .799 & .981 & .043 & 22.596 & $* * *$ & \\
\hline \multirow{4}{*}{$\begin{array}{c}\text { Confidence in } \\
\text { Government } \\
\text { Performance (HPG) }\end{array}$} & HPG1 & .552 & 1.000 & & & & \multirow{4}{*}{0.883} \\
\hline & HPG2 & .691 & 1.203 & .075 & 15.978 & $* * *$ & \\
\hline & HPG3 & .768 & 1.305 & .108 & 12.053 & $* * *$ & \\
\hline & HPG4 & .896 & 1.483 & .122 & 12.113 & $* * *$ & \\
\hline \multirow{3}{*}{$\begin{array}{c}\text { COVID-19 Vaccine } \\
\text { Confidence } \\
\text { (COVID19AG) }\end{array}$} & COVIDAG1 & .878 & 1.000 & & & & \multirow{3}{*}{0.830} \\
\hline & COVIDAG2 & .852 & .989 & .042 & 23.651 & $* * *$ & \\
\hline & COVIDAG3 & .837 & .982 & .042 & 23.188 & $* * *$ & \\
\hline
\end{tabular}

\footnotetext{
$* * *(\mathrm{p}<0.01)$
} 
Regression values show the power of observed variables to predict latent variables, that is, factor loadings. As can be seen in Table $1, \mathrm{p}$ value less than 0.05 for each factor means that the items are loaded correctly on the factors. In addition, the fact that the standardized regression coefficients are 0.552 and larger indicates that the power to predict the latent variables, that is, the factor loadings of each item is high. Structural relationship (path) coefficients between the variables are given in Table 2 below (Table 2).

Table 2. Research Model SEM Results

\begin{tabular}{|c|c|c|c|c|}
\hline Effects & Structural Relations & $\begin{array}{c}\text { Standardized } \\
\text { Regression } \\
\text { Coefficients }(\beta)\end{array}$ & $\mathrm{CR}$ & $\mathrm{p}$ \\
\hline \multirow{2}{*}{ Standardized Total Effect } & COVID19AG<---KSDG & .339 & 7,370 & \multirow{2}{*}{$* * *$} \\
\hline & COVID19AG<---HPG & .265 & 5,317 & \\
\hline \multirow{2}{*}{ Standardized Direct Effect } & COVID19AG<---KSDG & .339 & 7,370 & \multirow{2}{*}{$* * *$} \\
\hline & COVID19AG<---HPG & .265 & 5,317 & \\
\hline
\end{tabular}

When the standardized values of the total effects are examined, the total predictive power of the participants' Engaging in Preventive Health Behaviors (KSDG) and the COVID-19 Vaccine Confidence Level (COVID-19AG) was 0.339 units; it is seen that the total predictive power of the participants' confidence levels in government performance (HPG), COVID-19 vaccine confidence level (COVID-19AG) is 0.265 units. As a result, it was determined that the participants' engaging in preventive health behaviors $(\beta=0.339 ; p<0.05)$ and their level of confidence in government performance $(\beta=0.265 ; p<0.05)$ affected the COVID-19 vaccine trust levels in a statistically significant and positive way.

Table 3. Structural Model Goodness of Fit Indices

\begin{tabular}{cccc}
\hline General Model Fit & Good Fit & Acceptable Fit & Obtained Fit Values \\
\hline $\mathbf{x}^{2} / \mathbf{s d}$ & $\leq 3$ & $\leq 5$ & $\mathbf{4 . 0 0 6}$ \\
\hline NFI & $\geq 0.95$ & $\geq 0.90$ & $\mathbf{0 . 9 4 9}$ \\
\hline CFI & $\geq 0.97$ & $\geq 0.95$ & $\mathbf{0 . 9 6 1}$ \\
\hline IFI & $\geq 0.95$ & $0.94-0.90$ & $\mathbf{0 . 9 6 2}$ \\
\hline AGFI & $>0.95$ & $\geq 0.85$ & $\mathbf{0 . 9 0 8}$ \\
\hline GFI & $\geq 0.90$ & $0.89-0.85$ & $\mathbf{0 . 9 4 2}$ \\
\hline RMR & $<0.05$ & $<0.08$ & $\mathbf{0 . 0 7 2}$ \\
\hline
\end{tabular}

As seen in Table 3, the results obtained show that the fit indices of the proposed research model are at an acceptable level of fit. Criteria for determining structural equation modelling analysis model fit and measurement invariance were based on conventional standards $[48 ; 49 ; 50]$. The findings obtained with the structural equation analysis show that the construct validity of the model is provided.

\section{Conclusion}

The COVID-19 pandemic has affected the lives, health, and economic well-being of people around the world and has caused a significant change in the behavior of society. It has also created a strong incentive for people to get vaccinated. Vaccines are one of the effective interventions that can reduce the high burden of disease globally. For public health officials, however, public hesitations about vaccines pose an urgent problem. In addition, a safe and effective vaccine against COVID-19 has become a public health priority. In addition, to address the growing public health crisis created by the COVID-19 pandemic, governments around the world need to play an important role in preventing and controlling the disease while reducing the economic impact of COVID-19. Therefore, governments of many countries have implemented sensible measures and regulations (such as social distancing, hand washing, self-isolation, wearing masks, and stabilizing the economy) to prevent transmission of the disease [34]. However, it has been reported that the effective implementation of these measures depends on a high level of adaptability and positive support from the public. Emerging theoretical and empirical evidence has shown that trust in government is crucial for adherence to social policies based on public behavioral responses [23; 24]. Therefore, it is important for the control of COVID19 to investigate the effects of confidence in government performance and protective health behavior on trust in the COVID-19 vaccine during the epidemic period.

In this study, it was aimed to determine the effect of people's protective health behavior during the pandemic and their confidence in government performance on their confidence in the COVID-19 vaccine. In the same study, 400 middle and advanced age group individuals' protective health behaviors during the pandemic, their confidence levels in government performance, and their confidence in the COVID-19 vaccine were evaluated. The original value of the study, before this 
research, assessing the middle and advanced age group of the society's protective health behavior during the pandemic, the level of trust in government performance, and their confidence in the COVID-19 vaccine, and the state of people's protective health behavior and their trust in the government performance to their COVID-19 vaccine. The reason for this is that there is no other study that analyzes the effect on their trust with path analysis.

Considering the answers given by the individuals participating in the research to the survey; the mean value of showing protective health behavior was 4.48; the mean value of confidence levels in government performance was 3.81 , and the mean value of confidence levels in the COVID-19 vaccine was 3.94. Participants' levels of preventive health behavior, confidence in government performance, and confidence in the COVID-19 vaccine are above average; it was concluded that the individuals participating in the study exhibited a high level of preventive health behavior during the pandemic and generally had confidence in government performance and COVID-19 vaccines.

As a result of the data analysis, the first hypothesis of the research was accepted. In this direction, the protective health behavior of people during the pandemic has a statistically and significant effect on their confidence in the COVID-19 vaccine. In other words, when people show more and more accurate preventive health behavior during the pandemic, their COVID-19 vaccine acceptance and COVID-19 vaccine confidence increase. Similarly, the second hypothesis of the study was accepted. Accordingly, people's confidence in government performance during the pandemic has a statistically significant effect on their confidence in the COVID-19 vaccine. In other words, when people have more confidence in government performance during the pandemic, this increases their COVID-19 vaccine acceptance and their confidence in COVID-19 vaccines.

Confidence or distrust in government or the authorities in general has been reported to affect confidence in governmentissued or mandated vaccines and vaccination programmes. Also, beliefs that vaccine-preventable diseases are necessary to build immunity (beliefs that vaccines destroy important natural immunity) or that other behaviors (such as breastfeeding, traditional/alternative medicine) are as important as or more important than vaccination for maintaining health and preventing vaccine-preventable diseases. It has been stated that beliefs reduce vaccine confidence and increase vaccine hesitancy [35].

In other similar studies, it is stated that some actors deliberately polarize the vaccine debate and use questionable public and system weaknesses for political purposes [36, 37]; it has been reported that decreased confidence in the vaccine in other settings may be influenced by a wider climate of distrust in government and the scientific elite [38]. Similarly, Doherty et al. [39] found that a lack of trust in government predicted lower vaccine acceptance in all surveyed groups. Crawshaw et al. [40] emphasized that the distrust in the government in this process is a harbinger of vaccine hesitancy. Moreover, this result is consistent with previous findings that public trust is associated with commitment to public health interventions [41, 42, 43, 44]. Two different studies conducted in Liberia and Congo during Ebola outbreaks found that trust in government was positively associated with compliance with disease control measures [45] or the adoption of personal preventive behaviors (e.g. maintaining social distancing and accepting Ebola vaccines) [46].

It was also stated that making an accurate risk assessment about the epidemic is a prerequisite for the public sectors to initiate emergency response plans in a timely manner. For this reason, it has been reported that the collection and analysis of information about the scale and spread of the epidemic should be strengthened, personnel training should be made more rigorous, and consultancy experts should be highly qualified [1]. At the same time, timely and transparent publication of epidemic information by the authorities helps the public to be accurately informed about the situation and to take appropriate action. It has been stated that such proactive and transparent actions require more institutional flexibility and courage from the authorities [47].

\section{References}

[1] World Health Organization (2019). Coronavirus disease (COVID-19). https://www.who.int/docs/defaultsource/coronaviruse/situation-reports/20200529-covid-19-sitrep-130.pdf?sfvrsn=bf7e7f0c_4. 30 Mayıs 2020'de erişildi.

[2] Pal, M., Berhanu, G., Desalegn, C., ve Kandi, V. (2020). Severe Acute Respiratory Syndrome Coronavirus-2 (SARSCoV-2): An Update. Cureus, 12(3), e7423. doi:10.7759/cureus.7423.

[3] Tian, H., Liu, Y., ve Li, Y. et al. (2020). An investigation of transmission control measures during the first 50 days of the COVID-19 epidemic in China. Science, 368, 638-642. doi:10.1126/ science.abb6105.

[4] Kissler, S. M., Tedijanto, C., Goldstein, E., Grad, Y. H., ve Lipsitch, M. (2020). Projecting the transmission dynamics of SARS-CoV-2 through the postpandemic period. Science, 368(6493), 860-868. doi: 10.1126/science.abb5793.

[5] Phua, J., Weng, L., Ling, L. et al. (2020). Intensive care management of coronavirus disease 2019 (COVID-19): challenges and recommendations. Lancet Respir Med., 8(5), 506-517. doi: 10.1016/S2213-2600(20)30161-2.

[6] Nicola, M., Alsafi, Z., ve Sohrabi, C. et al. (2020). The socio-economic implications of the coronavirus pandemic (COVID-19): A review. International Journal of Surgery, 78, 185-193. doi: https://doi.org/10.1016/j.ijsu.2020.04.018. 
[7] Kaddoura, M., AlIbrahim, M., ve Hijazi, G. et al. (2020). COVID-19 Therapeutic Options Under Investigation. Front Pharmacol, 11, 1196. doi: 10.3389/fphar.2020.01196.

[8] World Health Organization (2020a). DRAFT landscape of COVID-19 candidate vaccines. https://www.who.int/whodocuments-detail/draft-landscape-of-covid-19-candidate-vaccines. 2 Haziran 2020 'de erişildi.

[9] Schwartz, J. L. (2020). Evaluating and Deploying Covid-19 Vaccines - The Importance of Transparency, Scientific Integrity, and Public Trust. N Engl J Med, 383(18), 1703-1705. doi:10.1056/NEJMp2026393.

[10] Ehreth, J. (2003). The value of vaccination: a global perspective. Vaccine, 21(27), 4105-4117. doi:10.1016/S0264410X(03)00377-3.

[11] Hajj Hussein, I., Chams, N., ve Chams, S., et al. (2015). Vaccines through Centuries: Major Cornerstones of Global Health. Front Public Health, 3, 269. doi:10.3389/fpubh.2015.00269.

[12] Salmon, D. A., Moulton, L. H., Omer, S. B., DeHart, M. P., Stokley, S., Halsey, N. A. (2005). Factors associated with refusal of childhood vaccines among parents of school-aged children: a case-control study. Archives of pediatrics \& adolescent medicine, 159, 470-476.

[13] Ropeik D. (2013). How society should respond to the risk of vaccine rejection. Human vaccines \& immunotherapeutics, 9, 1815-1818.

[14] Sadaf, A., Richards, J. L., Glanz, J., Salmon, D. A., ve Omer, S. B. (2013). A systematic review of interventions for reducing parental vaccine refusal and vaccine hesitancy. Vaccine, 31, 4293-304.

[15] T.C. Sağlık Bakanlığı II. Ulusal Aşı Çalıştayı, (2016). Çalıştay Raporu. 24-26 Mart $2016 . \quad$ Erişim: http://www.enfeksiyon.org.tr/2.calistayrapor.pdf. (Erişim Tarihi:03.03.2021).

[16] Rodriguez, H., Donner, W. R., ve Trainor, J. E. (2018). Handbook of disaster research. New York, NY: Springer International Publishing.

[17] Uslaner, E. M. (2018). The Oxford handbook of social and political trust. Oxford: Oxford University Press.

[18] Zmerli, S., ve Van der Meer, T. W. (2017). Handbook on political trust. Cheltenham, UK: Edward Elgar Publishing.

[19] Hetherington, M. J. (1998). The political relevance of political trust. American Political Science Review, 92(4), 791808. doi: $10.2307 / 2586304$.

[20] Rubin, G. J., Amlot, R., Page, L., ve Wessely, S. (2009). Public perceptions, anxiety, and behaviour change in relation to the swine flu outbreak: Cross sectional telephone survey. BMJ, 339, b2651. doi: 10.1136/bmj.b2651.

[21] Verger, P., Bocquier, A., Vergelys, C., Ward, J., ve Peretti-Watel, P. (2018). Flu vaccination among patients with diabetes: Motives, perceptions, trust, and risk culture - a qualitative survey. BMC Public Health, 18, 569. Doi: 10.1186/s12889018-5441-6.

[22] Taniguchi, H., ve Marshall, G. A. (2018). Trust, political orientation, and environmental behavior. Environmental Politics, 27(3), 385-410. https://doi.org/10.1080/09644016.2018.1425275.

[23] Chanley, V. A., Rudolph, T. J., ve Rahn, W. M. (2000). The origins and consequences of public trust in government - A time series analysis. Public Opinion Quarterly, 64(3), 239-256. doi:10.1086/317987.

[24] Lau, L. S., Samari, G., Moresky, R. T., Casey, S. E., Kachur, S. P., Roberts, L. F., ve Zard, M. (2020). COVID-19 in humanitarian settings and lessons learned from past epidemics. Nature Medicine, 26(5), 647-648. doi: 10.1038/s41591-0200851-2.

[25] OECD (2017). Trust and public policy: How better governance can help rebuild public trust. Paris: OECD Publishing.

[26] Al-Mohaithef, M., ve Padhi, B. K. (2020). Determinants of COVID-19 vaccine acceptance in Saudi Arabia: a web-based national survey. J Multidiscip Healthc. 13, 1657-1663. doi:10.2147/JMDH.S276771.

[27] Lazarus, J. V., Ratzan, S. C., ve Palayew, A. et al. (2020). A global survey of potential acceptance of a COVID-19 vaccine. Nat Med., 27(2), 225-228. doi: 10.1038/s41591-020-1124-9. 
[28] Coustasse, A., Kimble, C., ve Maxik, K. (2021). COVID-19 and Vaccine Hesitancy: A Challenge the United States Must Overcome. J Ambul Care Manage, 44(1), 71-75. doi: 10.1097/JAC.0000000000000360.

[29] MacDonald, N. E. (2015). Vaccine hesitancy: Definition, scope and determinants. Vaccine, 33(34), 4161-4164. doi: 10.1016/j.vaccine.2015.04.036.

[30] Schoch-Spana, M., Brunson, E. K., Long, R. et al. (2020). The public's role in COVID-19 vaccination: Human-centered recommendations to enhance pandemic vaccine awareness, access, and acceptance in the United States. Vaccine. doi: 10.1016/j.vaccine.2020.10.059.

[31] Lim, V. W., Lim, R. L., Tan, Y. R., Soh, A. S., Tan, M. X., ve Othman, N. B., et al. (2021). Government trust, perceptions of COVID-19 and behaviour change: Cohort surveys, Singapore. Bulletin of the World Health Organization, 99(2), 92-101. doi: 10.2471/BLT.20.269142.

[32] Han, Q., Zheng, B., Cristea, M., Agostini, M., Bélanger, J. J., Gützkow, B., Kreienkamp, J., ve Leander, N. P. (2021). Trust in government regarding COVID-19 and its associations with preventive health behaviour and prosocial behaviour during the pandemic: a cross sectional and longitudinal study. Psychological Medicine, 1-11. doi: 10.1017/S0033291721001306.

[33] Lin, Y., Hu, Z., Zhao, Q., Alias, H., Danaee, M., ve Wong, L. P. (2020). Understanding COVID-19 vaccine demand and hesitancy: A nationwide online survey in China. PLoS Negl Trop Dis, 14(12), e0008961. https://doi.org/10.1371/journal.pntd.0008961.

[34] World Health Organization (2020b). Coronavirus disease (COVID-19) advice for the public. Retrieved from https://www.who.int/emergencies/diseases/novel-coronavirus-2019/advice-for-public.

[35] The SAGE Vaccine Hesitancy Working Group (2013). What influences vaccine acceptance: A model of determinants of vaccine https://www.who.int/immunization/sage/meetings/2013/april/1_Model_analyze_driversofvaccineConfidence_22_March.pdf (Erişim Tarihi: 22.09.2021).

[36] Frew, P. M., Kriss, J. L., ve Chamberlain, A. T., et al. (2016). A randomized trial of maternal influenza immunization decision-making: a test of persuasive messaging models. Hum Vaccines Immunother, 12, 1989-96.

[37] Broniatowski, D. A., Jamison, A. M., ve Qi, S., et al. (2018). Weaponized health communication: Twitter bots and Russian trolls amplify the vaccine debate. Am J Public Health, 108, 1378-1384. doi:10.2105/AJPH.2018.304567.

[38] Larson, H. J., de Figueiredo, A., ve Xiahong, Z., et al. (2016). The state of vaccine confidence 2016: global insights through a 67-country survey. EBioMedicine, 12, 295-301.

[39] Doherty, I. A., Pilkington, W., ve Brown, L., et al. (2021). COVID-19 Vaccine Hesitancy in Underserved Communities of North Carolina. medRxiv. doi: doi: 10.1101/2021.02.21.21252163.

[40] Crawshaw, J., Konnyu, K., Castillo, G., van Allen, Z., Grimshaw, J. M., ve Presseau, J. (2021). Factors affecting COVID-19 vaccination acceptance and uptake among the general public: a living behavioural science evidence synthesis (v1.0, Apr 30th, 2021). Ottawa: Ottawa Hospital Research Institute, Apr 30. Erişim Tarihi 17 Ağustos 2021. https://www.mcmasterforum.org/docs/default-source/product-documents/living-evidence-syntheses/covid-19-living-evidencesynthesis-4.1---factors-affecting-covid-19-vaccination-acceptance-and-uptake-among-the-general-public.pdf?sfvrsn=5368712f_7

[41] Meredith, L. S., Eisenman, D. P., Rhodes, H., Ryan, G., ve Long, A. (2007). Trust influences response to public health messages during a bioterrorist event. Journal of Health Communication, 12(3), 217-232. https://doi.org/10.1080/10810730701265978.

[42] Mohseni, M., ve Lindstrom, M. (2007). Social capital, trust in the health-care system and self-rated health: The role of access to health care in a population-based study. Social Science \& Medicine, 64(7), 1373-1383. https://doi.org/10.1016/j.socscimed.2006.11.023.

[43] O’Malley, A. S., Sheppard, V. B., Schwartz, M., ve Mandelblatt, J. (2004). The role of trust in use of preventive services among low-income African-American women. Preventive Medicine, 38(6), 777-785. https://doi.org/10.1016/j.ypmed.2004.01.018.

[44] Salmon, D. A., Dudley, M. Z., Glanz, J. M., ve Omer, S. B. (2015). Vaccine hesitancy causes, consequences, and a call to action. American Journal of Preventive Medicine, 49(6), S391-S398. https://doi.org/10.1016/j.amepre. 2015.06.009. 
[45] Blair, R. A., Morse, B. S., ve Tsai, L. L. (2017). Public health and public trust: Survey evidence from the Ebola Virus Disease epidemic in Liberia. Social Science \& Medicine, 172, 89-97. https://doi.org/10.1016/j.socscimed.2016.11.016.

[46] Vinck, P., Pham, P. N., Bindu, K. K., Bedford, J., ve Nilles, E. J. (2019). Institutional trust and misinformation in the response to the 2018-19 Ebola outbreak in North Kivu, DR Congo: A population-based survey. Lancet Infectious Diseases, 19(5), 529-536. https://doi.org/10.1016/S1473-3099(19)30063-5.

[47] Zhao, W., Zhang, J., Meadows, M. E., Liu, Y., Hua, T., ve Fu, B. (2020). A systematic approach is needed to contain COVID-19 globally. Sci. Bull., 65(11), 876-878. https://doi.org/10.1016/j.scib.2020.03.024.

[48] Munro, B. H. (2005). Statistical Methods For Health Care Research (5th edition). Philadelphia: Lippincott Williams \& Wilkins.

[49] Brown, T. A. (2015). Confirmatory factor analysis for applied research (2nd Edition). New York: Guilford Press.

[50] Byrne, B. M. (2016). Structural equation modeling with AMOS: Basic concepts, applications, and programming (3rd Edition). Lawrence Erlbaum Associates.

[51] Zhou, F., Yu, T., Du, R., et al. (2020). Clinical course and risk factors for mortality of adult inpatients with COVID-19 in Wuhan, China: a retrospective cohort study. Lancet, 395, 1054. https://doi.org/10.1016/S0140-6736(20)30566-3

[52] Wang, D., Hu, B., Hu, C., et al. (2020). Clinical Characteristics of 138 Hospitalized Patients With 2019 Novel Coronavirus-Infected Pneumonia in Wuhan, China. JAMA, 323(11), 1061-1069. https://doi.org/10.1001/jama.2020.1585

[53] Chen, N., Zhou, M., Dong, X., et al. (2020). Epidemiological and clinical characteristics of 99 cases of 2019 novel coronavirus pneumonia in Wuhan, China: a descriptive study. Lancet, 395, 507. https://doi.org/10.1016/S0140-6736(20)30211-7

[54] Verity, R., Okell, L. C., Dorigatti, I., et al. (2020). Estimates of the severity of coronavirus disease 2019: a model-based analysis. Lancet Infect Dis., 20(6), 669-677. https://doi.org/10.1016/S1473-3099(20)30243-7 